\title{
O TROCA DE ESTILOS FABRICANDO JOVENS INCANSÁVEIS MUTANTES: UMA ANÁLISE COM OS ESTUDOS CULTURAIS
}

\author{
Ana Carolina Sampaio Zdradek ${ }^{1}$ \\ Dinah Quesada Beck ${ }^{2}$
}

\begin{abstract}
Resumo: A partir dos trechos extraídos do programa de televisão Troca de Estilos e das contribuições dos Estudos Culturais em Educação e da perspectiva teórica pós-estruturalista, buscamos analisar o exercício de pedagogias culturais que atuam educando mulheres, regulando suas condutas e operando sobre seus corpos por meio de discursos veiculados nesse artefato cultural. Finalizamos o artigo com reflexões e questionamentos que possibilitam repensar algumas "verdades" naturalizadas e que podem ser desconstruídas e/ou ressignificadas de modo a instigar os sujeitos a pensarem sobre as diferenças para além do corpo e do estilo vigente da moda.
\end{abstract}

Palavras-chave: Artefato Cultural; Corpo; Estudos Culturais

\section{THE TROCA DE ESTILOS BREWING YOUNG UNTIRING MUTANT: AN ANALYSIS WITH CULTURAL STUDIES}

\begin{abstract}
From extracted parts of the television program Troca de Estilos, contributions from Cultural Studies in Education and the post-structuralist theoretical perspective, we aim to analyze the exercise of cultural pedagogies that act educating woman, regulating their conduct and operating over their bodies through speeches served in this cultural artifact. We summarize this article with reflections and questioning that allow us to rethink some naturalized "truths" that might be deconstructed or resignfied, making subjects think about their differences beyond the body and the current fashion vogue.
\end{abstract}

Keywords: Cultural Arctifact; Body; Cultural Studies

\footnotetext{
${ }^{1}$ Mestra em Educação pela Universidade Federal do Rio Grande (FURG). Pesquisadora do Laboratório Nós do Sul - Estudos e Pesquisas sobre Identidades, Currículos e Culturas (IE/FURG).

${ }^{2}$ Doutora em Educação pela Universidade Federal do Rio Grande do Sul (UFRGS). Professora do Instituto de Educação da Universidade Federal do Rio Grande (FURG) e membro do Laboratório Nós do Sul - Estudos e Pesquisas sobre Identidades, Currículos e Culturas (IE/FURG).
} 


\section{ZAPEANDO INTENÇÕES}

“[...] desejos são construídos para que sonhemos com as inúmeras possibilidades de projetar e transformar nossos corpos. Vivemos em um mundo em que as "novidades" de consumo relativas ao corpo são diárias" MOMO e COSTA (2010, p. 980).

Cabelos arrumados, sapatos impecáveis, maquiagem e pele lisinha, este é o check list básico que introduzem naqueles/as que buscam por um visual aprovado e dentro da norma. Esta é a experiência de quem participa de um programa de televisão que visa regular e inferir sobre o estilo de uma pessoa. Muitos/as jovens ingressam nestes veículos na busca por uma aparência mais aceita em sociedade.

Ao fazermos um passeio pelos canais da televisão brasileira, um breve zapping, não é difícil encontrar na programação estes programas. Acompanhando a exposição dos/as participantes no Troca de Estilos e tomando a mídia como um espaço fértil de investigação, trazemos este programa em específico, destinado a mulheres e exibido no canal por assinatura Discovery Home \& Health. É possível mencionar que este atua na fabricação de determinados modos femininos de ser e estar na cultura.

Entendendo este programa enquanto um artefato cultural operador na produção de identidades culturais, buscaremos neste artigo analisar as pedagogias culturais que se exercitam nos veículos midiáticos do programa. Em um primeiro momento discorremos sobre a perspectiva da qual nos filiamos, os Estudos Culturais em Educação, sob o viés pós-estruturalista. Em um segundo momento, reforçamos a dimensão pedagógica deste programa e o exercício de pedagogias culturais que atuam educando mulheres e regulando condutas. Finalizamos trazendo alguns questionamentos produtivos para um repensar de algumas "verdades" naturalizadas e que podem ser desconstruídas de modo a instigar a pensar as diferenças, fora do corpo e do look perfeito.

\section{UM LUGAR PARA PENSAR E AGIR NO MUNDO}

Para os Estudos Culturais em Educação sob a vertente pós-estruturalista "é o olhar que botamos sobre as coisas que, de certa maneira, as constitui" (VEIGA-NETO, 2007, p. 30). Não cremos que ao lançarmos uma luz, iremos solucionar um problema com a razão, buscar sua fidedignidade, procuramos nos afastar dos grandes discursos, metanarrativas.

Este lugar do qual me nutro em teorizações férteis entende que a cultura é um espaço de disputas por significados, entende que existe um afrouxamento nas fronteiras 
institucionais e estas são desestabilizadas. Os Estudos Culturais não se configuram em disciplinas, de certa forma podemos entender seu legado como um campo de investigação que se quer ativamente antidisciplinar, (SILVA, 2013). As investigações que compartilham destes pressupostos iniciaram na Inglaterra na década de 1950 e questionavam as distinções entre a existência de uma "alta" cultura e uma "baixa" cultura, neste interim, toda produção que se dá na cultura é analisada, procuramos nas arestas alguns indícios e condições de possibilidades para compreender as chaves de inteligibilidades da qual são instituídos projetos de sociedade. Aqui entra em jogo a análise de “[...] instâncias, instituições e processos culturais tão diversos quanto exibições de filmes, livros de ficção, turismo, ciência, televisão, publicidade, medicina, artes visuais, música" (SILVA, 2001, p. 139). Os/as investigadores que compartilham este espaço de investigação buscam fugir de posições binárias, dualistas.

\footnotetext{
Tomando tais pressupostos como referência, talvez se deva começar dizendo que as investigações que compartilham dessa perspectiva teórica estão menos preocupadas em buscar respostas para o que as coisas de fato são, e se preocupam mais em descrever e problematizar processos por meio dos quais significados e saberes específicos são produzidos, no contexto de determinadas redes de poder, com certas consequências para determinados indivíduos e/ou grupos. (MEYER in: MEYER e PARAÍSO, p. 53).
}

De acordo com esta autora é exaltado o caráter produtor da linguagem nos Estudos Culturais e nas pesquisas pós-críticas de forma que precisamos agir desconfiando de tudo aquilo que é tomado como familiar e está naturalizado, aceito como uma verdade. A riqueza deste modus operandi se encontra na contingência, dos discursos que são tomados como atributos de certa época e lugar. Dessa maneira, são examinadas as condições históricas e sociais que levaram determinado objeto ou os sujeitos a "regimes de verdade" (FOUCAULT, 2010, p. 68), o filósofo nos provoca a pensar.

[...] a verdade seja rex sui, que a verdade seja lex sui, que a verdade seja judex sui. Quer dizer, que não é a verdade que é detentora e criadora dos direitos que ela exerce sobre os homens, das obrigações que esse tem a seu respeito e dos efeitos que eles esperam dessas obrigações, uma vez que e na medida em que se completam. Em outras palavras, não é a verdade que de qualquer modo administra seu próprio império, julga e sanciona esses que a obedecem e desobedecem. [grifos do autor]

As verdades quando naturalizadas e enraizadas numa cultura instituem um conjunto de saberes e práticas que regulam, estruturam e organizam a vida em sociedade. Na contemporaneidade, um conjunto de especialistas em uma área é 
convidado a falar publicamente para os indivíduos em sociedade suas "verdades científicas", portanto, um conjunto de indivíduos tornam-se produtos de um saber, produzidos por tal saber. De acordo com Tomaz Tadeu da Silva (2010) o sujeito não pensa, fala e produz, ele é constantemente, pensado, falado e produzido. Maurizio Lazzarato (2014, p. 73) complementa este pensamento dizendo que "as instituições públicas, a mídia, o Estado de bem estar social etc. devem ser considerados - sem metáfora - máquinas, pois eles agenciam (maquinam) multiplicidades (pessoas, procedimentos, semióticas, técnicas, regras, etc.)".

Nesse sentido, entra em jogo o que Paula Andrade e Marisa Costa (2013) chamam de hibridação entre Educação e Comunicação. As autoras problematizam que quando as dimensões educativas da cultura começaram a ser problematizadas em diferentes artefatos culturais, riquíssimas discussões atuaram enquanto deflagradoras nas análises de pedagogias culturais (GIROUX, 1995), as quais interessam na Educação, sendo uma fundamentação teórica empírica implicada na dimensão formativa e educativa dos artefatos da cultura contemporânea. Os estudos de Shirley Steinberg e Joe Kincheloe (1997) são importantes marcos dos estudos da mídia, juntamente com Roger Simon (2008) e Douglas Kellner (2008). Sobre a relevância dos estudos externos ao Brasil e dos internos a estudiosos/as brasileiros/as, Costa e Andrade (2013, p. 8) proferem:

\footnotetext{
Autores internacionais e brasileiros, enfoques ora mais culturalistas, ora mais foucaultianos da produtividade dos artefatos da mídia na construção de representações e de modos de ser, subsidiam as pesquisas sobre os modos como as pedagogias culturais operam. No conjunto de trabalhos em que o conceito de pedagogias culturais é ferramenta teórica central, os pesquisadores conseguem mostrar não só os efeitos de tais pedagogias, mas os modos como são produzidos.
}

Nesse preâmbulo é pertinente o conceito de pedagogias da sexualidade abordado no livro $O$ corpo educado organizado por Guacira Louro (2000), sob o qual traz uma importante contribuição aos Estudos Culturais e aos Estudos de Gênero brasileiros, nele, a autora toma a cultura como ponto de referência e articulação e afirma que a sexualidade é construída ao longo da vida de um indivíduo, sendo assim, ela é "aprendida". A autora nos mostra que os corpos são significados na cultura e por ela também são alterados a alvos de investimentos.

Num mundo de fluxo aparentemente constante, onde os pontos fixos estão se movendo ou se dissolvendo, seguramos o que nos parece mais tangível, a 
verdade de nossas necessidades e desejos corporais. O corpo é visto como a corte de julgamento final sobre o que somos ou o que podemos nos tornar. (LOURO 2000, p. 8)

Para tanto, buscamos nesta breve e contingente abordagem acerca dos Estudos Culturais, exaltar sua potência para pensarmos a multiplicidade de artefatos culturais que nos educam. Na próxima seção iremos trazer para o centro da análise o programa de televisão elencado para esta problematização a fim de compreender: Como as pedagogias culturais se exercitam no programa Troca de Estilos e que efeitos nas mulheres este artefato deseja produzir?

\section{“AMIGA, AMIGA MESMO, TE FALA A VERDADE".}

A cada semana, Gaby recebe duas mulheres que se conhecem muito bem, mas que não gostam do estilo uma da outra. Após ouvirem o que as mulheres têm a dizer, um trio de especialistas em beleza entrará em ação. [DHH, $2015]^{3}$

O programa Troca de Estilos tem como apresentadora a cantora brasileira, nascida no Pará, Gaby Amarantos, e como dito anteriormente, é produzido pelo canal Discovery Home \& Health. Os episódios inéditos vão ao ar na televisão brasileira todas às quartas-feiras, desde sua estreia no ano de 2015.

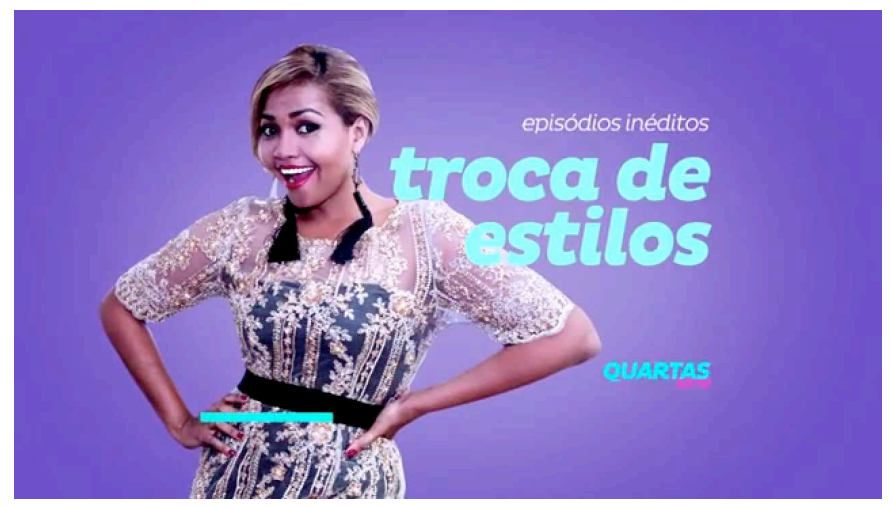

Figura 1 - Troca de Estilos. Disponível em: Google imagens.

Sobre esta imagem retomamos o título do artigo no qual mencionamos que as jovens se tornam constantes mutantes. Esta colocação foi proposta por Mariângela Momo (2007), ao discorrer acerca do tempo em que vivemos na contemporaneidade, um tempo de avidez e pressa. A autora se vale da metáfora da liquidez empregada por Zygmunt Bauman (2001) sobre a qual encontrou auxiliou para compreender as infâncias na sua pesquisa com crianças em uma escola da periferia de Porto Alegre/RS. Momo e

\footnotetext{
${ }^{3}$ Trecho retirado do site Discovery Mulher ao apresentar a série a seu público. Disponível em: http://discoverymulher.uol.com.br/beleza/troca-de-estilos-com-gaby-amarantos/ Acesso em: 20/03/2016. Os fragmentos apresentados deste site serão utilizados no decorrer do artigo na abreviação DHH, falas transcritas do site do Discovery Home \& Health.

Momento: diálogos em educação, E-ISSN 2316-3100, v. 26, n. 1, p. 30-43, jan./jun. 2017 
Costa (2010, p. 974) mencionam que "A utilização da linguagem televisiva é outro elemento frequente que compõe essa mutação dos sujeitos.”, ou seja, a linguagem televisiva interpela e estas vão ajudando a compor e descompor as identidades, forjando-as, de modo que as pessoas se vestem e travestem de costumes em uma maleabilidade rápida. Sobre o este fator Momo e Camozzato (2009, p. 38) mencionam:

\footnotetext{
Moda, estética, cirurgias, adereços e tatuagens são algumas das possíveis intervenções que demonstram o quanto o corpo vem sendo invadido, ressignificando e investigado. Outro exemplo pode vir da percepção de que nos mais variados espaços sociais as discussões estabelecidas giram em torno de uma "preocupação consigo", ou seja, os sujeitos contemporâneos são assolados por anseios que envolvem suas vidas por intermédio de aspectos relacionados ao corpo e aos modos de torna-lo mais desejado, sexy, bonito, jovial, produtivo.
}

Nesse sentido, explicitamos duas falas proferidas pelas participantes do programa, a primeira ao experimentar um sapato de salto alto que os/as especialistas entregam para ser calçado diz "Achei uó". No segundo caso uma jovem que gosta de usar shorts curtos e cabelo solto é convidada a vestir um blazer branco e uma saia longa e a mesma verbaliza "Eu estou me sentindo uma tia". As duas falas evidenciam um desconforto com a tentativa dos/as profissionais, da apresentadora e da amiga de melhorar a aparência das jovens.

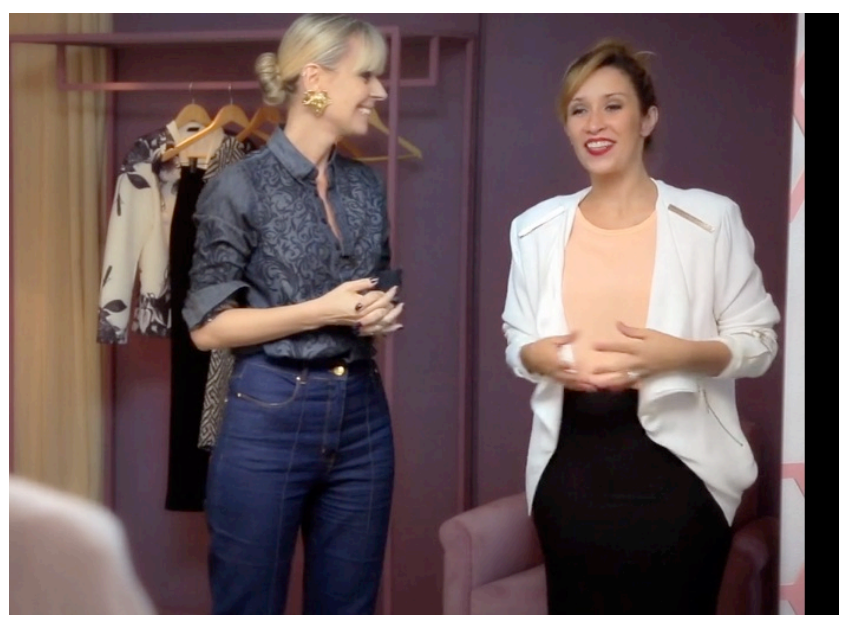

Figura 2 - Adaptado de https://vimeo.com/126986654 Acesso em: 25/03/2016

A foto acima é do episódio em que a jovem se sentiu uma tia com a roupa em questão. A especialista diz que ela ficou mais elegante e se mostra feliz com o resultado, porém a participante não. Com este visual milhões de mulheres estão sendo educadas a entender que esta maneira de se vestir que é a representação de alguém elegante. $O$ contrário, cabelo solto e short foram considerados pouco qualificados. Será mesmo? 
Qualificado para quem? Ao atentar-se a estas especificidades vale ressaltar que "Quando alguém ou algo é descrito, explicado, em uma narrativa ou discurso, temos a linguagem produzindo uma 'realidade', instituindo algo como existente de tal ou qual forma" (COSTA, 2000, p. 77).

Com relação ao público alvo deste programa no país, este parece endereçar-se a um determinado tipo de mulher jovem, de classe média alta, todas participantes do programa passam por alguns procedimentos estéticos como unhas feitas, cabelo escovado e maquiagem. Os especialistas do programa visam padronizá-las conforme o imperativo global de beleza. Segundo Gilles Lipovetsky e Jean Serroy (2011, p. 117) "Um cânone estético internacional triunfa, exaltando a mulher esbelta, o sex appeal, o glamour radiante, os cuidados consumistas com o corpo.”.

A partir da colocação dos autores é possível dizer que o triunfo deste cânone estético internacional impera, pois, os significados se querem globais, sendo assim, em outros países programas neste formato são disseminados. Importam-se programas e formatos de outras culturas e estas se entrecruzam em uma matize cultural. Um grande sucesso nos Estados Unidos foi o Esquadrão da moda ${ }^{4}$, estreado em 2003, contando ao total com 345 episódios, seu último episódio foi ao ar em 2013. Este programa também foi transmitido em Portugal, Canadá, Espanha e Brasil. Todos estes programas lidam com as fragilidades femininas, expondo o íntimo a público, abrindo guardaroupas/closets, lidando com as incertezas e frustrações. No Troca de estilos duas pessoas apontam defeitos entre si, em quem elas são e no que elas fazem para "parecer" quem elas são, a roupa precisa segundo os especialistas do programa ser condizente com o status profissional destas pessoas, marcando posições, fixando modelos. Bauman (2010) analisa este fator exponencial nas sociedades líquido-modernas, nos convida a pensar o corpo da mulher como este campo de pousio, como terras cultiváveis, um solo fértil para investimentos na aparência externa.

\footnotetext{
As tentações são muitas, a rede se espalha vastamente, há uma resposta para cada preocupação, de modo que quase toda mulher pode encontrar pelo menos um desejo que ela sinta ter se dirigido pessoalmente à sua autoestima e a seu orgulho, apontando um dedo acusador a ela e censurando-a por adotar uma abordagem morna demais em relação a seus deveres. (BAUMAN 2010, p. 191).
}

\footnotetext{
${ }^{4}$ Sob o nome original What Not to Wear, exibido no canal TLC - Discovery Networks Latin America. 
No caso do programa em questão, as participantes são sujeitas de muitos dedos acusadores, há uma regulação da vida (FOUCAULT, 1985). Comportamentos são justificados e requeridos na intensa composição e produção de si. Segundo Carmen Soares $(2013$, p. 75$)$ :

Talvez fosse importante pensar nas múltiplas táticas de modelagem e adestramento do corpo como uma história de contextos pedagógicos nos quais elas seriam mais um elemento. As pedagogias que se elaboram para educar o corpo incorporam, em seus lentos processos de constituição, as transformações da sensibilidade de cada época e, mais precisamente, uma racionalização da vigilância sobre o outro e sobre si mesmo, sobre o próprio corpo.

Neste contexto de vigilância sobre um corpo jovem é importante enfatizar que o ideário de juventude como um período de transição da infância para a idade adulta consiste em uma concepção gestada na Modernidade. Na contemporaneidade compreendemos que não se deve categorizar a juventude em uma fase. Alguns autores/as nos convidam a entender as juventudes enquanto um espaço alargado e escorregadio, existindo múltiplos modos de existência jovem. (GARBIN, RODRIGUES, PEREIRA, MANSKE, SANTOS, ROSSI e CAMOZZATO, 2006).

Investigar o modo como às mulheres jovens são educadas por instâncias culturais como a televisão consiste em apreendê-la como um instrumento de controle da esfera social. Os programas de televisão se disseminam em um rastro vertiginoso, alcançando visibilidade em outros produtos de audiência como os sites e as páginas alocadas nas redes sociais. Ao analisarmos a proliferação de um artefato em outros correlatos a ele, daremos atenção na próxima seção para página da emissora Discovery Home \& Health dedicada a mulheres, a qual anuncia o programa Troca de estilo na rede social Facebook, o nome da página é Discovery Mulher ${ }^{5}$.

\section{O DESEJO E A FÁBRICA DA CONFISSÃO.}

Existem também as conversas com um confidente, com amigos, com um guia ou diretor; às quais se acrescenta a correspondência onde se expõe o estado da própria alma, solicita-se conselhos, ou eles são fornecidos a quem deles necessita - o que, aliás, constitui um exercício benéfico até para aquele chamado preceptor, pois assim ele os reatualiza a si próprio: em torno dos cuidados consigo toda uma atividade de palavra e de escrita se desenvolveu, na qual se ligam o trabalho de si para consigo e a comunicação com outrem. (FOUCAULT, 1985, p. 57).

\footnotetext{
${ }^{5}$ Disponível em: https://www.facebook.com/DiscoveryMulher/?fref=nf. Acesso em 25/03/2016. 
O filósofo em questão menciona que no século XVII começa a ser posta a incitação de discursos sobre si. A igreja contribuiu nesse processo como receptora e condutora das confissões. Em $A$ vontade de saber Michel Foucault (1977) cita três características do dispositivo confessionário, são eles, a regularidade, a continuidade e a exaustividade. Ou seja, contar-se com frequência na produção de verdades sobre si de maneira contínua e com entrega sacrificial. Trazendo este fragmento histórico das elucidações do autor, podemos fazer o que nos Estudos Culturais chamamos de deslocamento, dessa maneira ao deslocar o olhar para a contemporaneidade é possível identificar as engrenagens que operavam nesta produção de si atuando nas redes sociais, blogs e diferentes ciberespaços que convocam diariamente os indivíduos a esta constante.

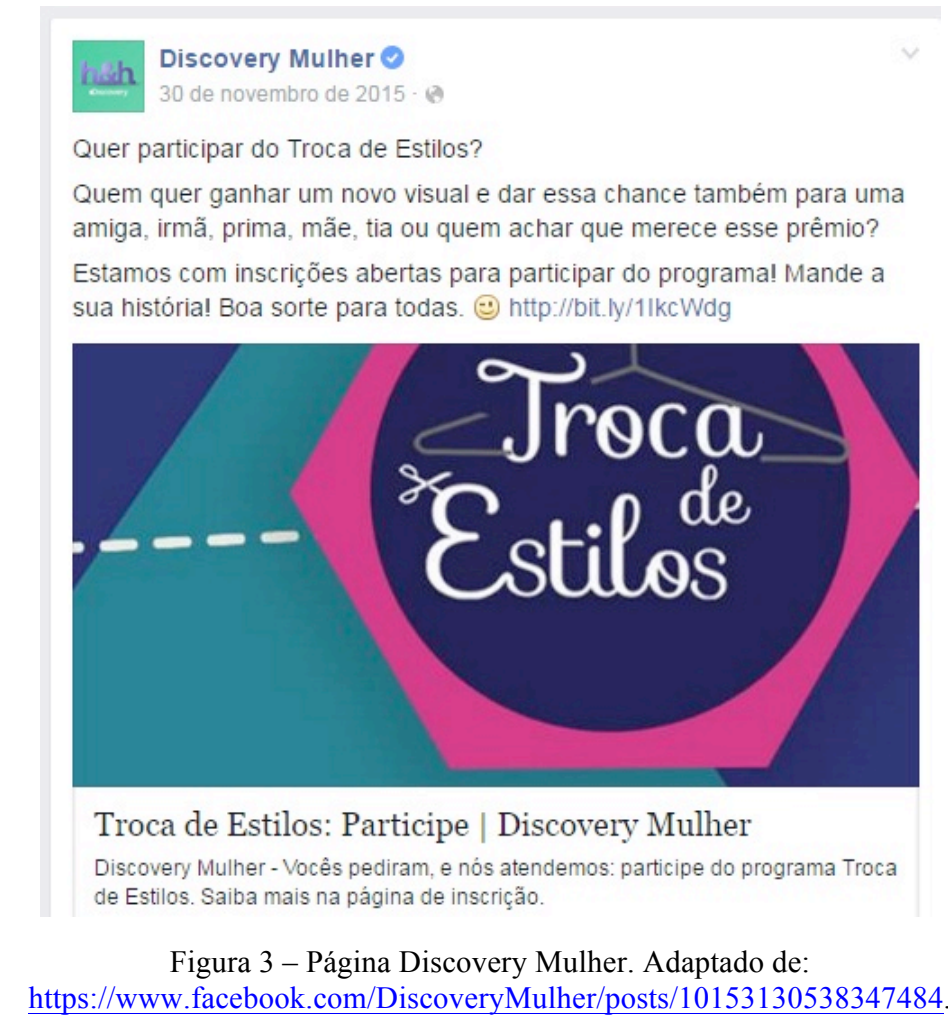

Acesso em: 25/03/2016.

No momento em que a página publica este convite para as seguidoras, é possível perceber nos comentários ${ }^{6}$ embaixo da postagem uma série de confissões carregadas com histórias da vida privada. O desejo por mudança na aparência convoca as confissões e colocações que subsidiam as justificativas. “[...] a mídia se faz um espaço de reduplicação dos discursos, dos enunciados de uma época”. Mais do que inventar ou

\footnotetext{
${ }^{6}$ Ipsis litteris. Todo excerto extraído do Facebook será mantido neste artigo como foi escrito pelos sujeitos na rede social.
}

Momento: diálogos em educação, E-ISSN 2316-3100, v. 26, n. 1, p. 30-43, jan./jun. 2017 
produzir um discurso, a mídia o reduplicaria, porém, sempre a seu modo, na sua linguagem, na sua forma de tratar aquilo que "deve" ser visto ou ouvido. (FISCHER, 2002, p. 86)

No espaço de duplicação dos discursos, neste imbricamento entre a mídia e o que é fabricado junto a ela trago um dos comentários da publicação acima, disposta na Figura 3, para reflexão. A seguidora J.M. F. menciona:

\begin{abstract}
"Quero participar pq tenho 25 anos e agora sou mãe e me perdi no que me vestir sou fotografa e gostaria de estar bem apresentada para meua clientes gostaria de participar com a minha mãe gostaria q ela participasse pois ela é linda nova mas sisma em se cobrir toda e $\mathrm{n}$ tem ninguém melhor do minha mãe para escolher oq eu me vestir" [excerto retirado do Facebook e publicado dia 16 de março às 12:42]
\end{abstract}

Ao tomarmos esta colocação, a primeira questão a ressaltar é a justificativa da idade, visto que o programa busca mulheres e se endereça para as que estão em uma faixa etária próxima dos 18 e 24 anos, a jovem se entrega narrando sua relação com a mãe no sonho de ser selecionada. A profissão também nos parece uma marca influente em seu posicionamento, logo uma fotógrafa precisa estar bem apresentada perante a sociedade no imaginário social. Quando Fischer (2002) tematiza acerca das linguagens e dos direcionamentos da maneira como algo deve ser "visto" ou entendido, acredito que nesta fala esteja expresso este caráter de circulação de significados. Que efeitos esta fala proferida pode causar em outras fotógrafas que tomarem contato com este fragmento? $\mathrm{O}$ Troca de Estilos está convocando estas moças a repensarem sua imagem como um cartão de visitas. Este mercado de consumo de aparências atua também como farmácias das almas na modernidade líquida (BAUMAN, 2011).

A pior sensação de mal-estar, uma espécie de metadesconforto que está na base de todas as inquietações específicas e que nos leva a repetir sem parar as visitas às farmácias consumistas, é a certeza de estarmos no caminho certo, a insegurança de não saber se nossas preferências são corretas do ponto de vista das avaliações em curso, se estamos fazendo as coisas direto e nos comportando de maneira adequada. (BAUMAN, 2011, p. 86).

Bauman nos provoca a pensar que tentar apaziguar problemas adquirindo novos objetos, sobressalentes é um costume cada vez mais frequente em um tempo de proliferação de incertezas. A seguidora da página P.S evidencia um pouco do cerne deste mal-estar contemporâneo em sua fala.

\footnotetext{
"Iria amar mudar aquele visual dela, rsrs. E principalmente ia mudar muito a minha auto estima q está muito baixa a respeito do meu visual. Seria meu presente de natal." [excerto retirado do Facebook e publicado 01/12/2015]
} 
Na contemporaneidade o consumo é um atributo da sociedade (BAUMAN, 2008), algumas dores e sofrimentos são amenizados com a compra de bens e sensações. Ao confessar-se e expor algumas angustias a público, outras pessoas vão aprendendo modos de existência e práticas sociais são gestadas e reproduzidas.

É isso que torna a Cultura tão central no mundo contemporâneo; é nisso - e a partir disso que estão falando aqueles que tratam os espaços e as práticas culturais como espaços e práticas que são também pedagógicos. Ao falarem em pedagogias culturais, eles estão salientando como e quando, fora dos espaços estritamente institucionalizados, se ensinam, se aprendem e se naturalizam determinadas verdades, visões de mundo e práticas sociais. (VEIGANETO, 2013, p. 18)

O Facebook nos parece este lugar onde se solicitam conselhos, dividem aflições, alguns proferem discursos de ódio, outros o fazem como espaço narcísico de superexposição de fotografias. O interessante é que ao analisarmos com as lentes dos Estudos Culturais e com as ferramentas teórico-conceituais disponibilizadas não procuramos significados ocultos, tudo nos parece estar muito bem-posto e articulado. A questão do marketing mesmo, não é o pano de fundo que rege este artefato cultural das mídias digitais, ela é condição de existência para tal veículo. Ao analisarmos como somos educados/as por estas instâncias e pela própria televisão estamos fazendo desta esfera cultural um espaço de disputas. Entendendo como SILVA (2001, p. 140) que "não se trata simplesmente de informação e entretenimento". Trata-se da maneira como estamos sendo significados e como a linguagem constrói saberes e poderes.

\section{POR UM MUNDO ONDE AS DIFERENÇAS DERRUBEM PADRÕES...}

[...] percebemos é que há uma pedagogia, um determinado tipo de currículo que opera através de uma lista de procedimentos e técnicas voltadas para produzir e reproduzir tipos específicos de comportamentos, valores, hábitos, atitudes pessoais diretamente conectadas com o tipo de sociedade na qual estão inseridos. É, sem dúvida, uma forma de regulação social que tem funcionado no sentido de manter tipos de espaços se segregação de gênero e de sexualidade. (SABAT 2001, p. 21).

Desejamos que as reflexões propostas abram fissuras e irrompam com um ideário que dite regras para vestirmos e estarmos na cultura. Uma página dedicada a assuntos "de mulher" na contemporaneidade parece ser um retrocesso em tantos avanços conquistados por mulheres no âmbito social. Dizemos isto tendo em vista a seleção de conteúdos feita pelo canal Discovery Home \& Health como sendo interesses da mulher contemporânea, a mesma é bastante carregada por conteúdos que não ultrapassam a fronteira da norma padrão, não é visibilizada uma mulher que irrompe 
com os valores tradicionais. Os códigos de feminilidade estão bem marcados em um direcionamento para mulheres que gostam de cozinhar e são donas de casa, investem bastante na aparência etc. $\mathrm{O}$ discurso publicitário que era vigente em propagandas da década de 1980 mostrando "as mulheres quase sempre dentro de casa, fazendo atividades manuais, ou expondo o corpo como objeto de prazer masculino" (SABAT, 2002, p. 14), ainda é vigente nos dias atuais, em uma rede de canais denominada Discovery, que seleciona para mulheres programas como Troca de Estilos e Guerra dos CupCakes e para homens seleciona programas de automóveis no Discovery Turbo. A página no Facebook Discovery Mulher é um exemplo da demarcação destes espaços. Estamos desejosas por um borramento entre estas fronteiras que ainda se mostram muito estanques.

Silva (2001) nos provoca a pensar a identidade e a diferença. As identidades são mutáveis, sendo assim, relacionais, porque são estabelecidas e assinaladas por uma marca simbólica relativamente a outras identidades. A diferença é então produzida e "não pode ser concebida fora dos processos linguísticos de significação" (SILVA, 2001, p. 87).

\begin{abstract}
Aqui, a representação não aloja a presença do "real" ou do significado. A representação não é simplesmente um meio transparente de expressão de algum suposto referente. Em vez disso, a representação é, como qualquer sistema de significação, uma forma de atribuição de sentido. Como tal, a representação é um sistema linguístico e cultural: arbitrário, indeterminado e estreitamente ligado a relações de poder. (SILVA, 2000, p. 6).
\end{abstract}

Esta compreensão se faz importante, pois, é a partir dos significados circulantes que os indivíduos vão tomando posições de sujeitos e sujeitas. No caso das mulheres representadas nas análises elencadas estas constituem apenas uma parcela de um território de disputas que não aloja múltiplos modos de ser mulher na contemporaneidade. A mídia analisada ajuda a forjar condutas se utilizando do espaço que lhe é destinado para instituir discursos e incitar a busca por corpos semelhantes.

A prática de contar-se a si mesmo contribui para alimentar as engrenagens da maquina social (LAZZARATO, 2014). As pessoas tendem a ocuparem-se consigo em uma vida cada vez mais individualizada, procura-se o outro na espera de uma aprovação ou reprovação. Segundo Maurício Ferreira (2012, p. 208) “as práticas de si já não se restringem apenas ao período da formação, mas, como já vimos, estende-se por toda vida do indivíduo". Neste sentido, torna-se cada dia mais primordial voltarmos nossas 
atenções para os diferentes modos com que as juventudes são educadas pela cultura e pelo modo como estas vão se constituindo sujeitos no interior dos saberes.

\section{Referências}

BAUMAN, Z. Vida para consumo. Rio de Janeiro: Zahar, 2008. . 44 cartas do mundo líquido moderno. Rio de Janeiro: Zahar, 2011.

COSTA, M. V. A educação na cultura da mídia e do consumo. Rio de Janeiro: Lamparina, 2009.

Mídia, magistério e política cultural. In: COSTA, Marisa Vorraber (Org.). Estudos culturais em educação. Porto Alegre: Ed. UFRGS, 2000, p. 73-91.

ANDRADE, P. D. de. Na produtiva confluência entre educação e comunicação, as pedagogias culturais contemporâneas. In: $36^{\circ}$ ANPED, Goiânia, 2013.

LIPOVETSKY, G; SERROY, J. A cultura mundo: resposta a uma sociedade desorientada. São Paulo: Companhia das letras, 2011.

FERREIRA, M. dos S. Espetacularização da carreira docente: prêmio professores do Brasil como prática da economia da educação.245f. (Tese) Doutorado em Educação, Universidade Federal do Rio Grande do Sul. (Faculdade de Educação, UFRGS), Porto Alegre, 2012.

FOUCAULT, M. História da sexualidade I: a vontade de saber. Rio de Janeiro: Graal; 1977.

História da sexualidade III: o cuidado se si. Rio de Janeiro: Graal, 1985.

Do Governo dos Vivos. Curso no Collège de France, 1979-1980 (excertos). Rio de Janeiro: Achiamé, 2010.

GARBIN, E. M.; RODRIGUES, A. C.; PEREIRA, A. S.; MANSKE, G. S.; SANTOS, L. G.; ROSSI, R. C.; CAMOZZATO, V. C.. Identidades Juvenis em Territórios Culturais Contemporâneos. Unirevista, v. 1, nº 2, 2006.

LAZZARATO, M. Signos, Máquinas, Subjetividades. São Paulo: Edições Sesc, 2014. LOURO, G. L. O corpo educado: pedagogias da sexualidade. Belo Horizonte: Autêntica, 2000.

MEYER, D. E.; PARAÍSO, M. A. (Orgs). Metodologias de Pesquisas Pós-Críticas em Educação. Belo Horizonte: Mazza Edições, 2013.

MOMO, M.; COSTA, M. V. Crianças escolares do séxulo XXI: para se pensar uma infầncia pós-moderna. Cadernos de pesquisa, v. 40, nº 141, p. 965-991, 2010.

; CAMOZZATO, V. O inescapável consumo de si mesmo: pensando a fabricação dos sujeitos contemporâneos. In: COSTA, M. V. (Org.) A educação na cultura da mídia e do consumo. Rio de Janeiro: Lamparina, 2009.

SABAT, R. Pedagogia cultural, gênero e sexualidade. Revista de Estudos Feministas, 09-4-21, 2001.

SILVA, T. T. da. (Org.) Identidade e Diferença: A perspectiva dos Estudos 
Culturais. Petrópolis, Editora Vozes, 2000.

. (Org.) Documentos de Identidade: uma introdução as teorias do currículo. Belo Horizonte, Autêntica, 2001.

Alienígenas na sala de aula: Uma introdução aos estudos culturais em educação.7.ed. Petrópolis, RJ: Vozes, 2013.

SOARES, Carmem Lúcia. Pedagogias do corpo: higiene, ginásticas, esporte. In: VEIGA-NETO, Alfredo; RAGO, Margareth (Org). Figuras de Foucault. Belo Horizonte: Autêntica, 2013.

FISCHER, Rosa Maria Bueno. O estatuto pedagógico da mídia: questões de análise. Educação \& Realidade, v. 22, nº 22, jul./dez. 1997, p. 59-80. 1997

Problematizações sobre o exercício de ver: mídia e pesquisa em educação. In: Revista Brasileira de Educação, n. ${ }^{0}$ 20. Campinas: Editores Associados/ANPEd, maio/jun./jul./ago., 2002, p. 83-94.

VEIGA-NETO, Alfredo; RAGO, Margareth (Orgs). Figuras de Foucault. Belo Horizonte: Autêntica: 2013.

Olhares. In: COSTA, Marisa Vorraber (Org): Caminhos Investigativos I: novos olhares na pesquisa em educação. Rio de Janeiro: Lamparina, 2007. 